RIVIEW ARTICLE

\title{
Endophytic fungi for sustainable agriculture
}

\author{
Abo Nouh FA* \\ Postgraduate student at Botany Department, Faculty of Science, Suez Canal University, Ismailia 45122, Egypt.
}

Abo Nouh FA 2019 - Endophytic fungi for sustainable agriculture. Microbial Biosystems 4(1), $31-44$.

\begin{abstract}
In view of health effects of pollution related with chemical fertilizers and pesticides, interest has increased to find alternative green methods of fertilization and control of pests. Fungal endophytes (endobionts) can be defined as the microfungi living within the tissues of plant without causing them probable disease symptoms. Endophytic fungi play an important role in the growth promotion and resistance to various biotic and abiotic stresses and diseases in plants. They also produce useful compounds as phytohormones, antimicrobial compounds, and many agrochemical bioactive metabolites. These endophytes hold huge potential to be used as safe and cost-effective alternative to chemical pesticides and fertilizers in view of their wide range of plant growthpromoting activities. The present review article describes the role of endophytic fungi in the agriculture sector.
\end{abstract}

Keywords - Abiotic stress, fungal endophytes, sustainable agriculture, plant growth promotion.

\section{Introduction}

Endophytic fungi are microfungi that internally infect living plant tissues without causing disease or any harm to plant, and live in mutualistic association with plants for at least a part of their life cycle (Kusari and Spiteller 2012; Anitha et al. 2013; Lugtenberg et al. 2016; Arora and Ramawat 2017; Jain and Pundir 2017; Lata et al. 2018; Khare et al. 2018; Chhipa and Deshmukh 2019). The term 'endophyte' is derived from two Greek words: 'endo' ='endon' meaning within, and phyte' = 'phyton' meaning plant, was first contrived by de Bary (1866) and denote all those microbes residing inside the living healthy plants (Kusari and Spiteller 2012; Lata et al. 2018; Chhipa and Deshmukh 2019). While few years before de Bary in 1846 Leveillé recognized the fungi in wheat leaves and called them as endophytic fungi (Lata et al. 2018).

Endophytes gain importance in recent past for their commercial and industrial exploitation. It was after landmark discovery of toxicosis caused by Neotyphodium coenophialum (Family Clavicipitaceae) in cattle eating the grass (Festuca arundinacea). It was recorded that the grass infected by the fungus without apparent symptoms. The fungus produces several toxic alkaloids which were the actual cause of toxicosis in cattle (Arora and Ramawat 2017).

Endophytes are ubiquitous in the plant world, no report of a plant species not associated to them is known; in a given plant species, individuals without endophytes are rare (Zabalgogeazcoa 2008). Evidence of plant-associated microorganisms found in the fossilized tissues of stems and leaves has revealed that endophytic-plant associations may have evolved $>400$ million years ago (Kusari and Spiteller 2012). During evolutionary process, plants change habitat from aquatic to terrestrial and were encountered with atmosphere with high carbon 
dioxide, poor soil nutrients and fluctuations in temperature and water availability. At the same time, endophytes have adapted themselves to the plant microenvironment by genetic variation including uptake of some plant's DNA (Arora and Ramawat 2017).

All types of microorganisms (fungi, bacteria, and actinobacteria) have been discovered as endophytes. The most frequently encountered endophytes are fungi (Strobel and Daisy 2003; Kusari and Spiteller 2012; Khare et al. 2018). Fungal endophytes may inhabit many different plant tissues includes, roots, stems, leaves (Khan et al. 2012); Branches, twigs, bark, fruit, and seeds (Torres et al. 2011); scales, resin canals and even from meristems (Arora and Ramawat 2017); petioles, flowers (Kumar et al. 2019) While some fungi are specific to certain plant family (Ali et al. 2018). The spectrum of fungi within a plant varies in space, time and function. For example, leaves, stems and roots of alfalfa plants are colonized by distinct fungi that produce different ranges of secondary metabolites (Lugtenberg et al. 2016).

This review offers a current and integrative account of endophytes in terms of their types, biodiversity, chemistry and their mechanism of action against abiotic stresses.

\section{Functional grouping of endophytic fungi}

In general, there are two major groups of endophytic fungi that reflecting differences in evolutionary relatedness, taxonomy, plant hosts, and ecological functions: the clavicipitaceous endophytes (C-endophytes), which infect some grasses; and the non clavicipitaceous endophytes (NC-endophytes), which can be recovered from vascular and non-vascular plant species (Rodriguez et al. 2009; Jain and Pundir 2017) (Table 1). Recently, fungal endophytes classify to sub-classes based on different criteria such as: host range, mode of reproduction, part of plant colonized, mode of transmission, source of nutrition, and ability to express symptoms in the host plant (Bamisile et al. 2018).

C-endophytes (Class 1 endophytes) including (Balansia spp. and Epichlö̈ spp.) represent a small number of phylogenetically related clavicipitaceous species that are fastidious in culture and limited to some cool- and warm-season grasses (Rodriguez et al. 2009; Khiralla et al. 2016). NC-endophytes are highly diverse, representing a polyphyletic assemblage of primarily ascomycetous fungi; they recovered from every major lineage of land plants, and from all terrestrial ecosystems, including both agro-ecosystems and biomes ranging from the tropics to the tundra (Rodriguez et al. 2009). NC-endophytes can be differentiated into three functional classes (Class 2, 3 \& 4 endophytes) based on host colonization patterns, mechanism of transmission between host generations, in planta biodiversity levels, and ecological function (Lugtenberg et al. 2016). The diverse class 2 endophytes encompass both Ascomycota and a few Basidiomycota. The highly diverse associates of above-ground tissues of nonvascular plants, seedless vascular plants, conifers, and woody and herbaceous angiosperms in biomes ranging from tropical forests to boreal and Arctic/Antarctic communities (Khiralla et al. 2016).

Endophytes from class 3 are extremely diverse and form highly localized infections in aboveground tissues, such as in the leaves of tropical trees and non-vascular and vascular plants (Lugtenberg et al. 2016). Class 4 endophytes are also referred to as the dark-septate endophytes (DSE) and these facultative biotrophic fungi colonize plant roots and having melanized dark septate hyphae are often ascomycetes belonging to the order Helotiales. They are found in the roots of almost 600 plant species and are present in a wide range of terrestrial ecosystems, but are especially common in polar and alpine habitats (Newsham 2011; Lugtenberg et al. 2016).

The source of endophytic colonization ranges from transmission via seeds and vegetative planting material to entrance from the surrounding environment such as the rhizosphere and phyllosphere (Lata et al. 2018). Fungal endophytes colonize the tissues of host by two routes: Vertical transmission of endophytic fungi take place from mother plant to offspring, via seeds, often referred to as "true endophytes", and Horizontal transmission occurs via soil or air-borne 
spores (Zabalgogeazcoa 2008; Yadav 2019). The already established plant endophytes may transmit from one generation to another generation via plant seeds (Lata et al. 2018).

Table 1 Symbiotic characteristics of fungal endophytic classes after Rodriguez et al. (2009).

\begin{tabular}{|c|c|c|c|c|}
\hline & Clavicipitaceous & Non-cla & icipitaceous & \\
\hline Criteria & Class 1 & Class 2 & Class 3 & Class 4 \\
\hline Host range & Narrow & Broad & Broad & Broad \\
\hline Transmission & Vertical \& horizontal & Vertical \& horizontal & Horizontal & Horizontal \\
\hline Tissue(s) colonized & Shoot \& rhizome & $\begin{array}{l}\text { Shoot, root } \quad \& \\
\text { rhizome }\end{array}$ & Shoot & Root \\
\hline In planta colonization & Extensive & Extensive & Limited & Extensive \\
\hline In planta biodiversity & Low & Low & High & Unknown \\
\hline Fitness benefits* & NHA & NHA \& HA & NHA & NHA \\
\hline
\end{tabular}

*Non habitat-adapted (NHA) benefits such as drought tolerance and growth promoting are common among endophytes regardless of the habitat of origin. Habitat-adapted (HA) benefits result from habitat-specific selective pressures such as $\mathrm{pH}$, temperature and salinity.

\section{Biodiversity of endophytic fungi}

Tropical and temperate rainforests are the most biologically diverse terrestrial ecosystems on earth represented $60 \%$ of the world's terrestrial biodiversity. The Competition is great, resources are limited, and selection pressure is at its peak. This gives rise to a high probability that rainforests are a source of biologically active compounds (Strobel and Daisy 2003). Almost all the plant species $(\sim 400,000)$ harbor one or more endophytic organisms (Anitha et al. 2013). The diversity and numbers of fungal endophytes vary considerably and their detection depends on biotic, abiotic and experimental factors. Usually one to a few species dominates the community, while the majority of the species are rare (Torres et al. 2011). Endophyte communities from higher latitudes are characterized by relatively few fungal species, whereas tropical endophyte are dominated by a small number of classes but a very large number of different endophytic species (Lugtenberg et al. 2016). Endophytic fungi are predominantly ascomycetes that appear to be ubiquitous in nature as they have been recovered from plants adapted to a wide range of ecosystems include hot deserts, Arctic tundra, mangroves, temperate and tropical forests, grasslands and savannahs, and croplands (Lugtenberg et al. 2016); extreme arctic, alpine and xeric environments (Ali et al. 2018). Xylariaceous Ascomycetes are the most dominant endophytes in tropical region. They found high endophytic diversity in the tropical plants in comparison to the temperate ones. Temperate region endophytes showed host specificity, while tropical region endophytes are less host specific (Chhipa and Deshmukh 2019). Endophytes have been isolated from plants growing in temperate to the tropic ecosystems, hot deserts, arctic tundra, mangroves, grasslands, savannahs, and cropland ecosystems (Chhipa and Deshmukh 2019). It is estimated that there are approximately more than one million endophytic fungal species worldwide which represent a significant genetic resource for biotechnology (Kumar et al. 2019).

\section{Rational for plant selection}

The understanding of methods and rationale for Plant Selection provides the best chance to isolate novel endophytic microorganisms (Strobel and Daisy 2003). Considering the enormous numbers and the diversity of plants, ingenious strategies should be utilized to narrow the search for endophytes producing plant compounds (Kusari and Spiteller 2012). We recommend that collecting endophytes for discovery of bioactive secondary metabolites should focus on both the host plants and the fungal taxa (Torres et al. 2011). According to (Strobel and Daisy, 2003; 
Kusari and Spiteller 2011; Torres et al. 2011; Lugtenberg et al. 2016) several hypotheses are governing the plant selection strategy: 1) Plants from a distinct ecological niche or with unusual biology might also harbor potent endophytes, 2) Plants with ethnobotanical history that are related to the specific uses or applications of interest, 3) Plants that are endemic, that have an unusual longevity, or that have occupied a certain ancient land mass, 4) Plants growing in areas of great biodiversity that housing endophytes with great biodiversity.

Plants from a distinct ecological niche or with unusual biology might also harbor potent endophytes Ex: Hypericum perforatum is very important medicinal plant occupying a significant place in ancient history. From the time of ancient Greece up till now extracts of $H$. perforatum are effective in treating mild or moderately severe depression (Cervo et al. 2002). H. perforatum commonly known as St. John's wort is an herbaceous perennial plant native to relatively dry temperature zones of Europe and North America (Çırak et al. 2010); H. perforatum has become a widely popular herbal remedy in recent years worldwide, used traditionally for the treatment of wounds and digestive disorders; and its crude extract is now extensively used in Europe as a drug for the treatment of depression (Kusari and Spiteller 2012).

Plants with ethnobotanical history that are related to the specific uses or applications of interest Ex: Juniperus plants contain the therapeutically important anticancer, also use of the oil of Juniperus species for the treatment of ulcers, carbuncles and leprosy (Kusari and Spiteller 2012). The Juniperus plant acts as an inhibitor in the acid environment. The inhibition efficiency increases with increase in inhibitor concentration but decreases with an increase in temperature (Al-Mhyawi 2014).

Plants that are endemic, that have an unusual longevity, or that have occupied a certain ancient land mass Ex: Camptotheca acuminata plant (Nyssaceae) is a tree, originally found in the mainland of China. The stem wood and the bark are known to contain several alkaloids (Hengel et al. 1992); grows in mainland China, and is commonly called the 'happy tree'. Plant has been in use as traditional medicine in China for treatment of psoriasis, liver and stomach ailments and the common cold (Kusari and Spiteller 2012). Camptothecin (CPT) is a waterinsoluble monoterpene derived indole alkaloid produced by the Chinese tree. Some semisynthetic CPT derivatives have anticancer activity along with its activity against retroviruses and parasites (Lorence et al. 2004).

Plants growing in areas of great biodiversity that housing endophytes with great biodiversity Ex: Azadirachta indica, commonly known as the Indian neem or Indian lilac, or 'dogonyaro' in Nigeria. Neem is a member of the mahogany family, Meliaceae (Atawodi and Atawodi, 2009). A. indica is well known in India its neighboring countries for more than 2000 years as one of the most versatile medicinal plants growing abundantly in regions having high biodiversity of plants (Kusari and Spiteller 2012). A. indica have many activities include: antiviral activity, antioxidant activity, Anti-inflammatory activity, Anticarcinogenic activity, Antibacterial activity, Antisnake venom activity, activity against Digestive disorders and parasitic diseases (Brahmachari 2004; Kumar and Navaratnam 2013).

In Egypt Abdel-Azeem and his coworkers studied the endophytic fungi associated with endemic and medicinal plants of Saint Katherine Protectorate in the arid Sinai, Egypt. For more details please consult the following reference : Salem and Abdel-Azeem 2014 ; Abdel-Azeem et al. 2016 ; 2018).

\section{Phytochemistry of endophytic fungi}

The endophytes produce certain phytochemicals as their host plants that may be related to a genetic recombination of the endophytes with the host. Many endophytes (biotypes) of the same species are isolated from the same plant and only one of the endophytes will produce a highly biologically active compound in culture (Strobel and Daisy 2003; Arora and Ramawat 
2017). The possibility that endophytes biosynthesize associated plant compounds was first comprehended and published by Stierle et al. (1993). Inspired by this discovery, numerous efforts have been made to identify endophytes as sources of associated plant natural products (Kusari and Spiteller 2012). Endophytic fungi have diverse secondary metabolites, some of which are bioactive compounds expressed as defensive weapons to protect the host plant from pests and diseases but also as metabolites for specific interactions and communications with the plant host. (Lugtenberg et al. 2016); and increase the adaptability of both endophytic fungi and their host plants to biotic and abiotic stresses (Jain and Pundir 2017; Ali et al. 2018). Endophytic fungi that live in desert plants are considered a vital source for many natural products (Ali et al. 2018).

Strategy for isolation, purification, identification, and characterization of most promising fungal endophytes for the purpose of sustainable agriculture development summarriez in Fig. (1) according to various studies carried by Strobel and Daisy (2003), Hassanein et al. (2016), Jain and Pundir (2017). The collected host tissue samples should be handled carefully and processed as quickly as possible, usually within 48 hours (Torres et al. 2011).

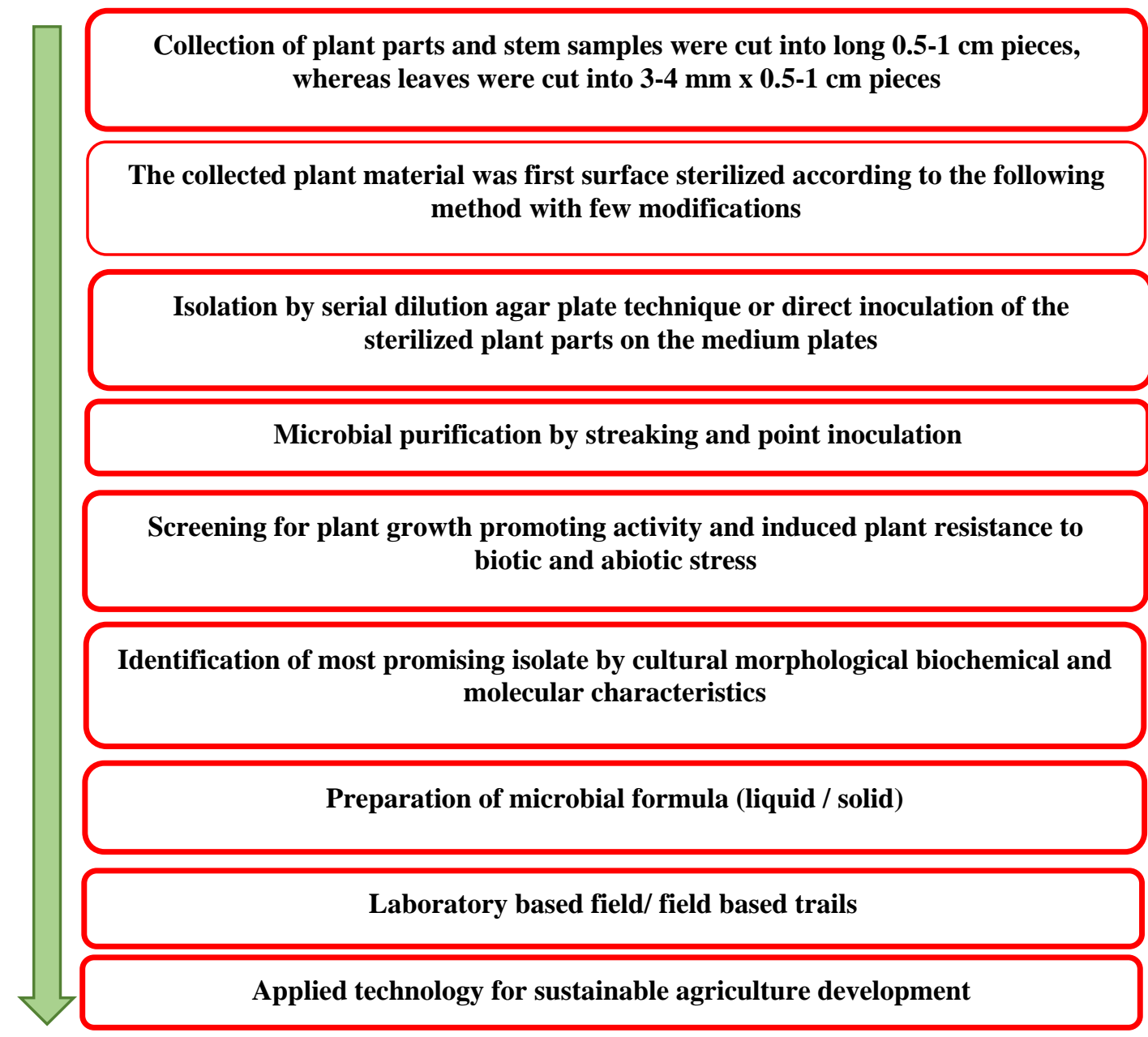

Fig 1 - A summarized strategy for isolation, identification and application of metabolities of endophytic fungi in agriculture. 


\section{Endophytic fungi Role in the ecosystem}

The symbiotic association of endophytic fungi with crops may responsible for an increase in crop growth and yield without supplementing extensive fertilizers (Rodriguez et al. 2008). Mutualistic fungi may confer tolerance to drought, metals, disease, heat, and herbivory, and/or promote growth and nutrient acquisition. It has become clear that at least some plants are unable to endure habitat-imposed abiotic and biotic stresses in the absence of fungal endophytes (Rodriguez and Redman 2008). These findings indicate that the incorporation of fungal symbionts may be a useful strategy in both mitigating impacts of climate change on major crops and expanding agricultural production onto marginal lands (Redman et al. 2011). The main action of Colonization by Endophytic fungi includes increase in the availability of nutrients, suppression of plant pathogens, nematodes and insects, phytohormone production, phytoremediation and rhizoremediation, and by conferring stress resistance to host plants. Different endophytes have the ability to fix, solubilize, and mobilize the micro- and macroelements for plant (Khan et al. 2012; Anitha et al. 2013; Zhoua et al. 2014; Jain and Pundir 2017; Arora and Ramawat 2017; Lata et al. 2018; Khare et al. 2018; Kumar et al. 2019).

There are evidences that the presence of endophyte may not only influence plant growth, developments, fitness and diversity but also population dynamic, plant community diversity and ecosystem functioning (Arora and Ramawat 2017). Endophytic fungi play a vital ecological functioning process in plant succession through the beneficial interaction between them which formed in the long-term ecosystem evolvement (Ali et al. 2018). The fungal endophytes have significant roles for living organisms and human health due to production of wide range of bioactive compounds. The endophytic fungi could potentially be used as future commercial bioinoculants and biocontrol agents for crops growing under the normal and abiotic stress conditions for sustainable agriculture and environments (Yadav 2019). The endophytic infection increases the microbial root colonization in plants by inducing production of root exudates which attract the rhizospheric microbes; therefore it makes convenient to degradation of complex minerals into simpler form and facilitates mineral transportation smooth from soil to plant (Chhipa and Deshmukh 2019).

\section{Habitat-adapted fitness benefits}

The concept that fungal endophytes adapt to stress in a habitat-specific manner was confirmed with different fungal and plant species, and different environmental stresses. This phenomenon defines as habitat-adapted symbiosis and hypothesize that fungal endophytes provide mechanism for plant adaptation to habitat stresses (Rodriguez et al. 2008). Fungal endophytes exhibit a range of symbiotic relationships with their hosts and various lifestyles including mutualism, commensalism, and parasitism (Strobel and Daisy 2003). There are several outcomes of symbiotic interactions defined by the fitness benefits to plant hosts and symbionts (Rodriguez and Redman 2008). Benefits to fungal symbionts can be positive (mutualism, commensalism and parasitism), neutral (amensalism and neutralism) or negative (competition). Benefits to host plants can also be positive (mutualism), neutral (commensalism and neutralism) or negative (parasitism, competition and amensalism) (Rodriguez et al. 2008; Khan et al. 2012; Lugtenberg et al. 2016; Lata et al. 2018). In addition, some endophytes may only exhibit a mutualistic interaction for one plant species, but not for another (Lugtenberg et al. 2016).

The fungal endophytes provide immune system to host plant to defend against phytopathogenic organisms (Jain and Pundir 2017) and helping plants to adapt to new habitats by making genetically, physiologically, and ecological modification to its host plants (Lugtenberg et al. 2016; Ali et al. 2018). It is important to understand microbe-microbe and plant-microbe interactions to generate/develop a beneficial soil microbiome. Physiochemical properties of soils have a direct influence on specific microbes and plant root exudates (Hussain 
et al. 2018). The genotype of host and fungus is an important factor to determine the establishment of symbiotic relation (Lata et al. 2018).

\section{Endophytic fungi for improving plant development}

Fungal endophytes can confer fitness benefits to plants including increased root and shoot biomass, increased yield, tolerance to abiotic stresses such as heat, salt, and drought, and to biotic stresses such as pathogens and herbivores (Rodriguez et al. 2008; Redman 2011) In fact, symbiotic fungi are responsible for the adaptation of plants to environmental stresses (Khan et al. 2012), and these tolerances can be transferred to agricultural plants (Rodriguez et al. 2008; Redman et al. 2011), these endophytes have been commercialized to improve agriculture in relation to climate changes, which involve increasing tolerance to drought and water stress and tolerance to high temperature and high salinity (Lugtenberg et al. 2016).

\section{Fungal endophytes for conferring biotic stress resistance and plant growth promoting}

Fungal endophytes are capable of protecting the plant against pathogens through various strategies, such as competition with pathogens for colonization and nutrients, the production of antibiotics, and the induction of resistance in the host plant (Kumar et al. 2019)

\section{Epichlö̈ species}

Epichloë sp. (Type II) Clavicipitaceous endophytes (Class 1) are endophytic symbionts form systemic associations with the aboveground tissues of grasses of cool-season grasses, and are one of the most economically important examples of plant-endophyte interactions (Rodriguez et al. 2009). Some species of Epichloë have lost the capacity for development of the sexual stage these have been referred to as asexual or Type III endophytes and are classified as species of Neotyphodium (Rodriguez et al. 2009). The symbiosis between Epichloë species and grasses is highly integrated involving the reciprocal use and manipulation of morphology, physiology, and life cycle and history traits of the partners to increase the fitness of the symbiota (Saikkonen et al. 2016) Neotyphodium and Epichloë of Festuca rubra is a plant growthpromoting endophyte which increase the plant growth with high uptake of nutrients (Jain and Pundir 2017; Chhipa and Deshmukh 2019). Endophytes Epichloe in temperate grass produce bioactive compounds in host plant which works as a deterrent to herbivores and pests (Chhipa and Deshmukh 2019). Epichloë endophytes have importance in pasture systems in delivering both economic and sustainable agricultural solutions (Lugtenberg et al. 2016).

\section{Piriformospora indica}

$P$. indica was originally isolated by Verma et al. (1998) from the rhizosphere of several xerophytic plants located in the Indian Thar dessert. This filamentous fungus belongs to the order Sebacinales in Basidiomycota. The endophyte promotes nutrient uptake, promotion of plant growth, confers resistance to pathogenic organisms and stimulates growth and seed production (Lugtenberg et al. 2016; Ali et al. 2018). P. indica interacts with many plant species including Arabidopsis. It colonizes the roots, grows inter- and intra-cellularly, forms pear-shaped spores within the cortex and extrametrical, and does not invade the endodermis and the aerial parts of the plants (Oelmüller et al. 2009). The root endophyte $P$. indica in barley confers disease resistance by a different mechanism. Symbiotic plants are thought to resist necrotrophic root pathogens due to increased activity of glutathione- ascorbate antioxidant systems (Waller et al. 2005). $P$. indica is enhanced barley grain yield, tolerance to mild salt stress and resistance against root and leaf pathogens, including the necrotrophic fungus Fusarium culmorum (root rot) and the biotrophic fungus Blumeria graminis. Beneficial effects are also observed for the crop for wheat, maize and rice (Oelmüller et al. 2009). $P$. indica is renowned for its broad host range, 
forming symbiotic root interactions with both mono- and dicotyledonous plants, including the agriculturally important barley, and the model plants, tobacco and Arabidopsis thaliana (Lugtenberg et al. 2016). Colonization of $P$. indica controlled various plant diseases such as powdery mildew, eyespot, Rhizoctonia root rot, Fusarium wilt, black root rot, yellow leaf mosaic, Verticillium wilt, cyst nematode, and leaf blight in barley, wheat, maize, tomato, and Arabidopsis plants. Reduced severity of Verticillium wilt by $30 \%$ in tomato caused by Verticillium dahlia, and increased leaf biomass by 20\% (Chhipa and Deshmukh 2019) The rootcolonizing facultative endophyte $P$. indica forms beneficial symbioses with crop plants. It has the potential for use in agriculture, horticulture and floriculture (Chhipa and Deshmukh 2019)

\section{Epicoccum nigrum}

E. nigrum is also known for its biocontrol potential against bacterial and fungal plant pathogens (Lugtenberg et al. 2016). The inoculation of an endophytic E. nigrum strain from an apple tree in the model plant Catharanthus roseus triggered defense responses against "Candidatus Phytoplasma mali" and reduced symptom severity (Fávaro et al. 2012). E. nigrum has shown biocontrol activity against bacterial pathogen pseudomonas savastanoi pv. Savastanoi (Psv) causing olive knot and reduced psv growth / biomass up to 96\% (Berardo et al. 2018). The isolate of sugarcane has shown biocontrol activity against fungal pathogen Sclerotinia sclerotiorum in sunflower and Pythium in the cotton crop, and have antibacterial activity against Phytoplasma in apple and Monilinia sp. in peach fruit and nectarines (Chhipa and Deshmukh 2019).

\section{Colletotrichum species}

Many Colletotrichum species have been shown to exist as endophytes for part or most of their lice cycle in many groups of plants (Pillai and Jayaraj 2015).the majority of Colletotrichum isolates fall within the gloeosporioides, graminicola, and boninense species complexes. Many endophytes isolated from grasses poaceae belong to the gloeosporioides and boninense species complexes (Sliva 2017). C. gloeosporioides isolated from healthy and mature leaves of tea plants show significant antagonistic activity against both the test pathogenic Pestalotiopsis theae and Colletotrichum camelliae. The degree of growth inhibition ranged from 51.77-63.73\% for P. theae and 18.33-36.73 \% for C. camelliae, respectively (Rabha et al. 2014). Endophyte $C$. gloeosporioides isolated from Theobroma cacao tissues showed antagonistic activity against black pod rot pathogen Phytophthora palmivora (causing black pod rot) Moniliophthora roreri (causing frosty pod rot), and M. perniciosa (causes witches broom) in in vitro and field studies (Chhipa and Deshmukh 2019).

\section{Trichoderma sp.}

Trichoderma sp. (teleomorph Hypocrea) is a fungal genus found in many ecosystems and the most successful biofungicides used in today's agriculture with more than $60 \%$ of the registered biofungicides world-wide (Mukherjee et al. 2012) Some strains have the ability to reduce the severity of plant diseases by inhibiting plant pathogens, mainly in the soil or on plant roots, through their high antagonistic and mycoparasitic potential (Hermosa et al. 2012). Trichoderma sp. uses several mechanisms such as antibiosis, myco-parasitism and competition for nutrients and space, and is also able to promote growth and development of plant and induce the defense response of plants (Talapatra et al. 2017). Trichoderma sp. has used as BCA against plant pathogenic fungi such as Botrytis cinerea, Fusarium spp., Pythium app., and Rhizoctonia spp. (Park et al. 2019). The endophytic fungi T. viride showed antagonistic activity against all the fungi except Aspergillus but hyphae of $T$. viride overgrew on pathogen mycelium (Talapatra et al. 2017). T. citrinoviride isolated from mountain- cultivated ginseng (Panax ginseng) has 
fungal activity against Botrytis cinerea, Pythium spp., Rhizoctonia solani, and cylindrocarpon destrutans (Park et al. 2019). Trichoderma sp. produced different secondary metabolites; these compounds reported as a plant defense activator in canola, pea, and tomato (Chhipa and Deshmukh 2019).

\section{Fungal entomopathogens}

Entomopathogenic fungi (EPF) (Ascomycota: Hypocreales) are commonly found in diverse habitats and are known as insect biocontrol. These fungi have also been found as rhizosphere colonizers in the surrounding environment of the host plant (Vega et al. 2008). Recent evidence suggests that certain EPF species have the potential to engage in fungus-plant interactions, as fungal endophytes or plant disease antagonists, without causing any immediate negative effect or even promoting growth of host plants (Vega et al. 2008). most of the commercially produced entomopathogenic fungi can be endophytic for part of their life cycle and include the species of Beauveria, Metarrhizium, Lecanicillium and Isaria (Lugtenberg et al. 2016); they are effective against several root-feeding insects belonging to different orders, such as the root mealy bug, Cataenococcus ensete, the sugar beet root maggot, Tetanops myopaeformis, the diabroticine rootworms, and the white grubs Melolontha and Popillia japonica (Lugtenberg et al. 2016). Beauveria bassiana is an entomopathogenic fungus with worldwide distribution, which can live as a plant endophyte; colonization of plant tissues by $B$. bassiana has proved to provide protection against insect damage and inhibition of insect establishment and development (Vega et al. 2008; Allegrucci et al. 2017). Fungal endophytes $B$. bassiana and Clonostachys rosea collected of coffee plants from Hawaii, Colombia, Mexico and Puerto Rico appeared to be pathogenic to the coffee berry borer (Hypothenemus hampei) that is the most devastating pest of coffee throughout the world (Vega et al. 2010). The endophytic growth of $B$. bassiana in corn plant tissues by cause higher mortality of larvae of the European corn borer (Ostrinia nublialis Hbn) (Vidal 2015). B. bassiana was able to infect T. absoluta (leaf miner pest of tomato leaves) either by direct contact with conidia or indirectly by ingestion of tomato leaves colonized endophytically result in mortality up to $50 \%$ or higher, (Allegrucci et al. 2017).

\section{Fungal endophytes for conferring abiotic stress resistance}

Abiotic stresses represent a significant threat to agricultural productivity. A global water shortage due to significant climatic changes is the leading cause of these abiotic stresses including drought, extreme temperatures, salinity (Redman 2011; Hussain et al. 2018). The agricultural, coastal and geothermal plant endophytes conferred disease, salt and heat tolerance, respectively (Rodriguez et al. 2008). Medicinal plants are reported to harbor endophytes, which in turn provide protection to their host from infectious agents and also provide adaptability to survive in adverse environmental conditions. (Anitha et al. 2013). Fungal endophytes help plants to adapt under the abiotic stress of temperature, $\mathrm{pH}$, salinity and drought via indirect mechanisms e.g. through induced systemic resistance (ISR), bioremediation, biocontrol (Yadav 2019). The plant's root colonized with $P$. indica showed tolerance in different abiotic stresses like extreme temperature, salinity, drought, heavy metals (Oelmüller et al. 2009; Chhipa and Deshmukh 2019).

\section{Drought Stress}

Plant growth is greatly affected by drought stress and plants must adapt to this stress to survive (Oelmüller et al. 2009). Endophytes may direct the plant metabolism for the secretion of soluble sugars, amino acids such as proline, polyols, and alkaloids that confer wall elasticity and osmotic adjustment during drought condition (Jain and Pundir 2017). Drought is the most 
significant abiotic stress, adversely affecting the productivity and distribution of crop plants worldwide. For example, drought alone affects up to $45 \%$ of the global agricultural land (Hussain et al. 2018).

Interestingly, all fungal endophytes conferred drought tolerance to plants regardless of the habitat of origin (Rodriguez et al. 2008). Curvularia protuberata (Cp4666D) and Fusarium culmorum (FcRed1) isolates from geothermal soil and Costal Beach Both conferred similar levels of drought tolerance in tomato (Rodriguez et al. 2008). Epichloë species may enhance the eco-physiology of host plants and enable plants to counter abiotic stresses such as drought and metal contamination. $N$. coenophialum infection leads to the development of extensive root systems that enable plants to better acquire soil moisture and absorb nutrients, resulting in drought avoidance and faster recovery from water stress (Rodriguez et al. 2009). Endophyte associated plants (panic grass, rice, tomato and dune grass) have been reported to use significantly less water, increased biomass than in non-symbiotic plants. The drought tolerance phenomenon may be explained by enhanced accumulation of solutes in tissues of endophyteinfected plants as compared to non-infected plants (Lata et al. 2018). Lavender plants inoculated with Glomus intraradices and Glomus sp. strain accumulated these compounds and exhibited high drought tolerance by improving water contents, root biomass and $\mathrm{N}$ and $\mathrm{P}$ contents (Hussain et al. 2018). Neotyphodium sp. increased drought tolerance in grass plant by osmo- and stomatal regulations and protected plants in water stress and nitrogen starvation (Chhipa and Deshmukh 2019). Penicillium brevicompactum isolated from wild barley species was helpful in drought tolerance improvement of barley plant in drought condition (Chhipa and Deshmukh 2019).

\section{Salinity Stress}

Salinity limits agricultural production in arid and semiarid areas, characterized by low annual precipitation, where agriculture is dependent on irrigation. Increased salt ion concentrations (such as $\mathrm{Na}^{+}$and $\mathrm{Cl}^{-}$, but also others including $\mathrm{Ca}^{2+}, \mathrm{K}^{+}, \mathrm{CO}_{3}{ }^{2-}, \mathrm{NO}_{3}{ }^{-}, \mathrm{SO}_{4}{ }^{2-}$ ) in soil reduce water uptake by roots which ultimately results in the accumulation of toxic salt ions within plant cells (Hussain et al. 2018). F. culmorum isolate FcRed1 from dunegrass is a mutualist in dunegrass colonized species from both plant groups conferred salt tolerance to rice (monocot) and tomato (eudicot), and isolates from non-coastal plants do not confer salt tolerance (Rodriguez et al. 2008). Redman et al. (2011) showed that some class 2 fungal endophytes can confer salt and drought tolerance to two commercial rice varieties which were not adapted to these stresses. Moreover, these endophytes reduced water consumption by $20 \%-30 \%$ while increasing growth rate, reproductive yield and biomass of greenhouse grown plants. Inoculation with arbuscular mycorrhizal fungi (AMF) significantly improved salt tolerance and improved yield in tomato; maize, mungbean, clover and cucumber due to $\mathrm{P}$ acquisition, improved osmoregulation by proline accumulation and reduced $\mathrm{NaCl}$ concentration (Hussain et al. 2018). Penicillium sp. and Phomaglomerata Significantly increased plant biomass, related growth parameters, assimilation of essential nutrients such as potassium, calcium, magnesium and reduced the sodium toxicity in cucumber plants under salinity and drought stress, when compared with control plants (Lata et al. 2018). Trichoderma sp. and $P$. indica showed drought and salt tolerance in cacao, barley, and Chinese cabbage plant (Chhipa and Deshmukh 2019).

\section{Extreme temperature stress}

The Intergovernmental Panel on Climate Change (IPCC: 2007) reported that global temperatures are predicted to increase by $1.8-3.6{ }^{\circ} \mathrm{C}$ by the end of this century due to climate changes. High temperatures are a major obstacle in crop production as well as microbial colonization, which results in major cellular damage such as protein degradation and aggregation (Hussain et al. 2018). Class 2 endophytes confer heat tolerance to plants growing in geothermal 
soils (Rodriguez et al. 2008). Curvularia protuberata from Dichanthelium lanuginosum growing in the geothermal soils of Lassen Volcanic and Yellowstone National Parks able to confer heat tolerance to the host plant (Ali et al. 2018). The ability of the grass D. lanuginosum to survive soil temperatures ranging between $38 \circ \mathrm{C}$ and $65 \circ \mathrm{C}$ in Yellowstone National Park was directly linked to an association with the fungus $C$. protuberata and its mycovirus, Curvularia thermal tolerance virus (CThTV) (Lata et al. 2018; Kumar et al. 2019). Curvularia sp. confer thermos tolerance to grasses, and also provided thermos tolerance ability to other plants tomato, watermelon, and wheat (Chhipa and Deshmukh 2019).

\section{Conclusion}

Recently, there has been an ever-increasing interest in finding eco-friendly and safe approaches to increase agriculture productivity. Fungal endophytes are important components of sustainable agriculture in view of their ability to produce various compounds e.g. phytohormones and solubilize phosphates, siderophore production, inhibiting plant pathogens, and promoting plant growth. Keeping in mind that fungal endophytes are sustainable mines for production the various beneficial products and the number of investigations carried out has shown a sharp increase to study plant-fungus associations in the last decade. In the coming years, the use of genetically modified endophytes will be focused to improve plant yields and defensive properties.

\section{Acknowledgements}

The author would like to thank Prof. Ahmed M. Abdel-Azeem for suggesting the point of this review and his continuous support and the two anonymous reviewers for their valuable suggestions.

\section{References}

Abdel-Azeem A. M., Zaki S. M., Khalil W. F., Makhlouf N. A. and Farghaly L. M. 2016. Antirheumatoid Activity of Secondary Metabolites Produced by Endophytic Chaetomium globosum. Frontiers in Microbiology, 7 (1477): 1-11.

Al-Mhyawi S. R. 2014. Inhibition of mild steel corrosion using Juniperus plants as green inhibitior. African Journal of Pure and Applied Chemistry, 8(1): 9-22.

Ali A. H., Radwan U., El-Zayat S. and El-Sayed M. A. 2018. Desert Plant-Fungal Endophytic Association: The Beneficial Aspects to their Hosts. Biological Forum - An International Journal, 10(1): 138-145.

Allegrucci N., Velazquez M. S., Russo M. L., Perez E. and Scorsetti A. C. 2017. Endophytic colonisation of tomato by the entomopathogenic fungus Beauveria bassiana: the use of different inoculation techniques and their effects on the tomato leafminer Tuta absoluta (Lepidoptera: Gelechiidae ). Journal of Plant Protection Research, 57 (4): 205-211.

Anitha D., Vijaya T., Pragathi D., Reddy N.V., Mouli K.C., Venkateswarulu N. and Bhargav D.S. 2013. Isolation and Characterization of Endophytic Fungi from Endemic Medicinal plants of Tirumala Hills. international journal of life sciences biotechnology and pharma research, 2(3):367-373.

Arora J. and Ramawat K.G. 2017. An Introduction to Endophytes. In: D.K. Maheshwari (ed.), Endophytes: Biology and Biotechnology, Sustainable Development and Biodiversity 15, pp. 1-16. Swizterland: Springer International Publishing AG. DOI:10.1007/978-3-31966541-2_1.

Atawodi S. E., and Atawodi J. C. 2009. Azadirachta indica (neem): a plant of multiple biological and pharmacological activities. Phytochem. Rev. 80: 601-620.

Bamisile B. S., Dash C. K., Akutse K. S., Keppanan R. and Wang L. 2018. Fungal Endophytes : 
Beyond Herbivore Management. Frontiers in Microbiology, 9(544): 1-11.

Berardo C., Bulai I.M., Baptista P., Gomes T. and Venturino E. 2018. Modeling the endophytic fungus Epicoccum nigrum action to fight the "olive knot" disease caused by Pseudomonas savastanoi pv. savastanoi (Psv) bacteriain Olea europea L. trees. In: R. P. Mondaini (ed.), Trends in Biomathematics: Modeling, Optimization and Computational Problems, pp. 189207. Swizterland: Springer International Publishing AG.

Brahmachari G. 2004. Neem-An Omnipotent Plant: A Retrospection. Chem Bio Chem, 5: 408421.

Cervo L., Rozio M., Guiso G., Morazzoni P. and Caccia S. 2002. Role of hyperforin in the antidepressant-like activity of Hypericum perforatum extracts. Psychopharmacology, 164: 423-428.

Chhipa H., and Deshmukh S.K. 2019. Fungal Endophytes: Rising Tools in Sustainable Agriculture Production. In: S. Jha (ed.), Endophytes and Secondary Metabolites, pp.1-24, Swizterland: Springer International Publishing AG.

Çırak C., Bertoli A., Pistelli L. and Seyis F. 2010. Essential oil composition and variability of Hypericum perforatum from wild populations of northern Turkey. Pharmaceutical Biology, 48(8): 906-914.

de Bary A. 1866. Morphologie and physiologie der Pilze, Flechten, and Myxomycten. In Hofmeister's. Handbook of Physiological Botany.2: Leipzig.

Fávaro L. C. D. L., Sebastianes F. L. D. S. and Araujo W. L. 2012. Epicoccum nigrum P16, a Sugarcane Endophyte , Produces Antifungal Compounds and Induces Root Growth. PLoS ONE, 7(6): 1-10. DOI:10.1371/journal.pone.0036826

Hassanein N. M., El-Gendy M. M. and Abdelhameed N. M. 2016. Endophytic fungi of some medicinal plants in Egypt. Egyptian Academic Journal of Biological Sciences, 8(1): 65-78.

Hengel A. J. Van, Harkes M. P., Wichers H. J., Hesselink P. G. M. and Reinetta M. 1992. lines of Camptotheca acuminata. Plant Cell, Tissue and Organ Culture, 28: 11-18.

Hermosa R., Viterbo A., Chet I., Monte E. and Monte E. 2012. Plant-beneficial effects of Trichoderma and of its genes. Microbiology, 158: 17-25.

Hussain S. S., Mehnaz S. and Siddique K. H. M. 2018. Harnessing the Plant Microbiome for Improved Abiotic Stress Tolerance. In: D. Egamberdieva and P. Ahmad (ed.), Plant Microbiome: Stress Response. Volume 5: Microorganisms for Sustainability, pp. 21-43. Singapore: Springer Nature. DOI: 10.1007/978-981-10-5514-0_2

Jain P. and Pundir R.K. 2017. Potential Role of Endophytes in Sustainable Agriculture-Recent Developments and Future Prospects. In: D. K. Maheshwari (ed.), Endophytes: Biology and Biotechnology, Sustainable Development and Biodiversity 15, pp. 145-160. Swizterland: Springer International Publishing AG. DOI:10.1007/978-3-319-66541-2_1.

Khan S. A., Hamayun M., Khan A. L. and Shinwari, Z. K. 2012. Isolation of plant growth promoting endophytic fungi from dicots inhabiting coastal sand dunes of Korea. Pakistan Journal of Botany, 44(4): 1453-1460.

Khare E., Mishra J. and Arora N.K. 2018. Multifaceted Interactions Between Endophytes and Plant: Developments and Prospects. Frontiers in Microbiology, 9 (2732): 1-12.

Khiralla A., Spina R., Yagi S., Mohamed L. and Laurain-Mattar D. 2016. Endophytic Fungi: Occurrence, Classification, Function and Natural Products. In: E. Hughes (ed.). Endophytic fungi: diversity, characterization and biocontrol, pp. 1-19. New York, USA: Nova Science Publisher.

Kumar V. S. and Navaratnam,V. 2013. Neem (Azadirachta indica): Prehistory to contemporary medicinal uses to humankind. Asian Pacific Journal of Tropical Biomedicine, 3(7): 505514.

Kumar V., Soni R., Jain L., Dash B. and Goel R. 2019. Endophytic Fungi : Recent Advances in 
Identification and Explorations. In: B. P. Singh (ed.), Advances in Endophytic Fungal Research, Fungal Biology, pp. 267-281. Swizterland: Springer International Publishing AG. DOI 10.1007/978-3-030-03589-1_13

Kusari S. and Spiteller M. 2012. Metabolomics of Endophytic Fungi Producing Associated Plant Secondary Metabolites : Progress, Challenges and Opportunities. Metabolomics, In: Ute Roessner (Ed.), Pp. 241-266. Rijeka, Croatia: InTech.

Lata R., Chowdhury S., Gond S. and White J. F. 2018. Induction of abiotic stress tolerance in plants by endophytic microbes. Applied Microbiology, 66(4): 268-276.

Léveillé, J. H. 1846. Considerations mycologiques suivis d'une nouvelle classification des champignons. Paris.

Lorence A., Medina-Bolivar F. and Nessler C. L. 2004. Camptothecin and 10-hydroxy camptothecin from Camptotheca acuminata hairy roots. Plant Cell Rep, 22: 437-441.

Lugtenberg B. J. J., Caradus J. R. and Johnson L. J. 2016. Fungal endophytes for sustainable crop production. FEMS Microbiology Ecology, 92 (12): p.1-17.

Mukherjee M., Mukherjee P. K., Horwitz B.A., Zachow C., Berg G., and Zeilinger S. 2012. Trichoderma-Plant-Pathogen Interactions: Advances in Genetics of Biological Control. Indian J Microbiol, 52(4): 522-529.

Newsham K. K. 2011. A meta-analysis of plant responses to dark septate root endophytes. New Phytologist, 190: 783-793.

Oelmüller R., Sherameti I., Tripathi S., Varma A., Jena F., Botanik A. and Str D. 2009. Piriformospora indica, a cultivable root endophyte with multiple biotechnological applications. Symbiosis, 49: 1-17.

Ogorek R. and Plaskowska E. 2011. Epicoccum nigrum biocontrol agents in vitro of plant fungal pathogens. Communications in agricultural and applied biological sciences, 76(4): 691697.

Park Y., Mishra R. C., Yoon S., Kim H., Park C., Seo S. and Bae H. 2018. Endophytic Trichoderma citrinoviride isolated from mountain-cultivated ginseng (Panax ginseng) has great potential as a biocontrol agent against ginseng pathogens. Journal of Ginseng Research, 43: 408-420.

Pillai T. G. and Jayaraj R. 2015. Colletotrichum gloeosporioides: A True Endophyte of the Endangered Tree , Cynometra travancorica in the Western Ghats Plant. Journal of Plant Pathology \& Microbiology, 6(5): 1-5.

Rabha A. J., Naglot, A., Sharma G. D. and Gogoi H. K. 2014. In Vitro Evaluation of Antagonism of Endophytic Colletotrichum gloeosporioides Against Potent Fungal Pathogens of Camellia sinensis. Indian J Microbiol, 54(3): 302-309.

Redman R. S., Kim Y. O., Woodward, C. J. D. A., Greer C., Espino L., Doty S. L. and Rodriguez R. J. 2011. Increased Fitness of Rice Plants to Abiotic Stress via Habitat Adapted Symbiosis: A Strategy for Mitigating Impacts of Climate Change. PLoS ONE, 6(7): 1-10. DOI /10.1371/journal.pone.0014823

Rodriguez R. and Redman R. 2008. More than 400 million years of evolution and some plants still can't make it on their own: plant stress tolerance via fungal symbiosis. Journal of Experimental Botany, 59(5): 1109-1114.

Rodriguez R. J., Henson J., Volkenburgh E. Van and Hoy M. 2008. Stress tolerance in plants via habitat-adapted symbiosis. International Society for Microbial Ecology Journal, 2: 404416.

Rodriguez R. J., White J. F., Arnold A. E. and Redman R. S. 2009. Fungal endophytes: diversity and functional roles. New Phytologist, 182(2): 314-330.

Saikkonen K., Young C. A., Helander M. and Schardl C. L. 2016. Endophytic Epichloë species and their grass hosts : from evolution to applications. Plant Molecular Biology, 90(6): 665- 
675.

Salem F. M. and Abdel-Azeem A. M. 2014. Screening of Anticancer Metabolites Produced by Endophytic Fungi. LAP LAMBERT Academic Publishing. ISBN 978-3-659-53697-7.

Silva D. D. D. E., Crous P. W., Ades P. K., Hyde K. D. and Taylor P. W. J. 2017. Life styles of Colletotrichum species and implications for plant biosecurity. Fungal Biology Reviews, 31(3): 155-168.

Strobel G. and Daisy B. 2003. Bioprospecting for Microbial Endophytes and Their Natural Products. Microbiology and molecular biology reviews, 67(4): 491-502.

Talapatra K., Das A. R., Saha A. K. and Das P. 2017. In vitro antagonistic activity of a root endophytic fungus towards plant pathogenic fung. Journal of Applied Biology \& Biotechnology, 5(2): 68-71.

Torres M., Tadych M., White J. F. and Bills G. F. 2011. Isolation and identification of fungal endophytes. Prospects and Applications for Plant Associated Microbes: A Laboratory Manual, Part B: Fungi. In: A. M. Pirttila and S. I. Sorvari (ed.), pp. 153-164. Turku, Finland: BBI (Biobien Innovations).

Vega F. E., Posada F., Aime M. C., Pavaripoll M., Infante F. and Rehner S. A. 2008. Entomopathogenic fungal endophytes. Biological Control, 46: 72-82.

Vega F. E., Simpkins A., Aime M. C., Posada F., Peterson S. W., Rehner S. A., Infante F., Castillo A. and Arnold A. E. 2010. Fungal endophyte diversity in coffee plants from Colombia , Hawai'i , Mexico and Puerto Rico. Fungal Ecology, 3(3):122-138.

Verma S., Varma A., Rexer K-H., Hassel A., Kost G., Sarbhoy A., Bisen P., Bütehorn B. and Franken P. 1998. Piriformospora indica, gen. et sp. nov., a new root-colonizing fungus. Mycologia, 90(5): 896-903.

Vidal S. 2015. Entomopathogenic fungi as endophytes: plant-endophyte-herbivore interactions and prospects for use in biological control. Current science, 109(1): 46-54.

Waller F., Achatz B., Baltruschat H., Fodor J., Becker K., Fischer M., Heier T., Ralph Hückelhoven, H., Neumann C., Wettstein D.V., Franken P. and Kogel K-H. 2005. The endophytic fungus Piriformospora indica reprograms barley to salt-stress tolerance, disease resistance, and higher yield. Proc. Natl. Acad. Sci. U.S.A., 102:13386-13391. doi: 10.1073/pnas.0504423102

Yadav A. N. 2019. Endophytic Fungi for Plant Growth Promotion and Adaptation under Abiotic Stress Conditions. Acta Scientific Agriculutre, 3(1): 91-93.

Zabalgogeazcoa I. 2008. Fungal endophytes and their interaction with plant pathogens. Spanish Journal of Agricultural Research, 6: 138-146.

Zhou Z., Zhang C., Zhou W., Li W., Chu L. and Yan J. 2014. Diversity and plant growthpromoting ability of endophytic fungi from the five flower plant species collected from Yunnan, Southwest China. Journal of Plant Interactions, 9(1): 585-591. 